\title{
PENSAMENTOS E INTELECTUAIS NEGROS(AS) DA APNB - ASSOCIAÇÃO DE PESQUISADORES(AS) NEGROS(AS) DA BAHIA: NARRATIVAS INSURGENTES E EDUCAÇÃO ANTIRRACISTA
}

\author{
Luiz Gustavo Santos da Silva
}

\begin{abstract}
RESUMO
Escritos iniciais de uma pesquisa que está sendo desenvolvida no Programa de Pós-Graduação em Educação da Universidade do Estado do Rio de Janeiro - ProPED/UERJ, teço algumas reflexões sobre a Associação de Pesquisadores(as) Negros(as) da Bahia e seu surgimento, considerando-a um espaço ativo, local de encontro que produz microrresistências, onde fronteiras do conhecimento hegemônico são problematizadas e/ou deslocadas. Lugar onde intelectuais negros(as) articulam táticas (CERTEAU, 1998) e disputas no campo da memória e da produção educacional antirracista, firmando-se enquanto uma territorialidade específica. Considero a importância dos estudos sobre suas histórias de vida, narrativas e produções, ressaltando suas contribuições e experiências para/com a formação de professores(as) e educação das relações étnico-raciais, tendo como pano de fundo a Lei 10.639/03. O texto aproxima-se da proposta teórica dos estudos de Bakthin, em especial a polifonia e adota a história oral enquanto procedimento metodológico.
\end{abstract}

Palavras-chave: Intelectuais negras(os). Formação de professores(as) e educação antirracista. Conhecimentos contra-hegemônicos. Polifonia.

\section{BLACK INTELLECTUALS AND THOUGHTS - BAHIA BLACK RESEARCHERS ASSOCIATION: INSURGENT NARRATIVES AND ANTI-RACIST EDUCATION}

\begin{abstract}
Initial writings of a research that is being developed in the Graduate Program of Education of the State University of Rio de Janeiro - ProPED / UERJ, I make some reflections on the Association of Black Researchers of Bahia and its emergence, considering it an active space, a meeting place that produces micro resistances, where hegemonic knowledge boundaries are problematized and / or displaced. Place where black intellectuals articulate tactics (CERTEAU, 1998) and disputes in the field of memory and anti-racist educational production, establishing themselves as a specific territoriality. I consider the importance of studies on their life histories, narratives and productions, highlighting their contributions and experiences to / with the formation of teachers and education of ethnic-racial relations, against the background of Law 10.639 / 03. The text approaches the theoretical proposal of Bakthin's studies, especially polyphony and adopts oral history as a methodological procedure.
\end{abstract}

Keywords: Black intellectuals. Teacher training and anti-racist education. Counterhegemonic knowledge. Polyphony.

\footnotetext{
${ }^{1}$ Doutorando pelo programa de Pós-Graduação em Educação da Universidade do Estado do Rio de Janeiro - ProPED (UERJ), Linha de Pesquisa Cotidianos, Redes Educativas e Processos Culturais. Bolsista FAPERJ, é pesquisador do Grupo FIRMINA - PÓS-COLONIALIDADE: Educação, História, Cultura e Ações Afirmativas (UNEB), na Linha de Pesquisa Pensamentos e Intelectuais negras(os): diálogos e combates contemporâneos e do Grupo de Pesquisa Culturas e identidades no cotidiano (ProPED - UERJ) 


\title{
PENSAMIENTOS E INTELECTUALES NEGROS APNB - ASOCIACIÓN DE INVESTIGADORES NEGROS DE BAHIA: NARRATIVAS INSURGENTES Y EDUCACIÓN ANTIRRACISTA
}

\begin{abstract}
RESUMEN
Escritos iniciales de una investigación que se está desarrollando en el Programa de Posgrado de Educación de la Universidad Estatal de Río de Janeiro - ProPED / UERJ, hago algunas reflexiones sobre la Asociación de Investigadores Negros de Bahía y su surgimiento, considerándolo un espacio activo, un lugar de encuentro que produce micro resistencias, donde los límites del conocimiento hegemónico son problematizados y / o desplazados. Lugar donde los intelectuales negros articulan tácticas (CERTEAU, 1998) y disputas en el campo de la memoria y la producción educativa antirracista, estableciéndose como una territorialidad específica. Considero la importancia de los estudios sobre sus historias de vida, narrativas y producciones, destacando sus contribuciones y experiencias a / con la formación de maestros y la educación de las relaciones étnico-raciales, en el contexto de la Ley 10.639 / 03. El texto aborda la propuesta teórica de los estudios de Bakthin, especialmente la polifonía, y adopta la historia oral como un procedimiento metodológico.
\end{abstract}

Palabras clave: Intelectuales negros(os). Formación de docentes y educación antirracista. Conocimiento contrahegemónico. Polifonía.

\section{INTRODUÇÃO}

Este artigo traz reflexões preliminares sobre os(as) intelectuais negros(as) e a Associação Baiana de Pesquisadores(as) Negros(as) da Bahia - APNB, pesquisa desenvolvida no Programa de Pós-Graduação em Educação da Universidade do Estado do Rio de Janeiro ProPED/UERJ. O interesse pela temática nasceu a partir de encontros no grupo de pesquisa Firmina - Pós - Colonialidade, Educação, História, Cultura e Ações Afirmativas - na Linha de Pesquisa Pensamentos e Intelectuais negras(os): diálogos e combates contemporâneos, vinculado à Universidade do Estado da Bahia, depois de conversas minhas com estes(as) mesmos(as) intelectuais que participaram ativamente da construção desta associação.

A pesquisa insere-se no campo de estudos dos cotidianos (ALVES, 2008; GARCIA, 2011; OLIVEIRA, 2013; PASSOS, 2014), considerando duas questões fundamentais: a primeira, dar a devida importância, neste espaçotempo ${ }^{2}$ (APNB), não àquilo que se mostra enquanto repetição e reprodução, mas principalmente o que sutilmente escapa e está presente como criação anônima do "homem comum", como "astúcia", "tática de resistência", “invenção". (CERTEAU, 1998, p. 97) A segunda é entender que refletir sobre as narrativas de intelectuais negros(as) é algo complexo que exige uma escuta atenta das experiências que emergem dessas conversas. As questões desenvolvidas com estes(as) intelectuais negros(as) se

\footnotetext{
${ }^{2}$ Esta junção de palavras é proposital. Busca a superação de determinadas dicotomias e fragmentações herdadas do discurso hegemônico da modernidade e, ao mesmo tempo, possibilitar a produção de outros sentidos a partir dessa união. Escrita inspirada em Nilda Alves (FERRAÇO; GOMES, 2015)
} 
darão a partir do campo temático da educação das relações étnico-raciais na formação inicial e continuada de professores(as) e serão amparadas no que determina a Lei 10.639/2003 que alterou a atual Lei de Diretrizes e Bases da Educação Nacional, tornando obrigatório incluir nos currículos oficiais das redes de ensino - pública e privada - a temática História e Cultura AfroBrasileira e Africana.

Passados dezesseis anos da implementação da lei, pergunto: há conformação de quadros de pensamentos ou de estudos, veiculados e/ou mesmo produzidos pela APNB que versam sobre a formação de professores(as) e educação das relações étnico-raciais hoje no estado da Bahia? Se sim, essas produções têm encontrado terreno fértil para debates no campo educacional e luta antirracista na Bahia e/ou mesmo no Brasil? Apesar de fundamentais para a pesquisa, as limitações deste artigo não me permitem desenvolver tais questões nesse momento. Os esforços aqui se concentrarão em discorrer sobre a importância das narrativas dos(as) intelectuais negros(as) que compõem a história da APNB e suas possíveis contribuições para este debate.

Discutir o espaçotempo da formação docente (inicial e continuada) no cotidiano é repensar a compreensão linear do próprio termo "formação" que é cunhado na crença dos "atos inaugurais", restrito aos processos de certificação e treinamento. É entender que essa formação, muitas vezes aportada em concepções hegemônicas e homogeneizadoras de conhecimentos, valoriza apenas os saberes científicos fundamentados e instituídos como "neutros", reproduzindo discursos de igualdade e universalidade de direitos. Temos aqui os saberes científicos produzidos por essa Ciência maiúscula, que fala por todos e todas, pensados, conduzidos e instituídos a partir dos interesses e das questões daqueles(as) cujas vozes indeterminadas pretenderam (e pretendem) representar toda a humanidade. Paradigmas hegemônicos, baseados na propriedade da Verdade e que ao longo dos últimos quinhentos anos inspiraram a filosofia e as ciências ocidentais daquilo denominado por Grosfoguel (2008) como sistema - mundo patriarcal/capitalista/colonial/moderno. (GROSFOGUEL, 2008)

O importante aqui é problematizar o conceito de ciência e contingenciar suas produções.

A ciência moderna não foi, nos dois últimos séculos, nem um mal incondicional nem um bem incondicional. Ela própria é diversa internamente, o que lhe permite intervenções contraditórias na sociedade. E a verdade é que foi (e continua a ser) muitas vezes apropriada por grupos sociais subalternos e oprimidos para legitimar as suas causas e fortalecer as suas lutas. (SANTOS; MENESES, 2009, p. 11).

Assim sendo, qualquer conhecimento válido é sempre contextual, tanto em termos de diferença cultural como em termos de diferença política. Para além de certos patamares de 
diferença cultural e política, as experiências sociais são constituídas por vários conhecimentos, cada um com seus critérios de validade, ou seja, são constituídas por conhecimentos rivais. (SANTOS; MENESES, 2009)

Os lugares de formação docente e educação antiracista não estão alheios a estes contextos já que são espaçostempos também atravessados por processos políticos e culturais que constituem ou mesmo posicionam socialmente sujeitospraticantes (OLIVEIRA, 2012) com diferentes concepções de vida, visões de mundo, histórias e trajetórias diversas, tecendo experiências e sentidos no fazer-se professor(a). Sendo assim, refletir sobre o campo de pesquisa da formação docente e educação das relações étnico-raciais a partir do que dizem os intelectuais negros(as) da APNB, valorizando as suas experiências e histórias de vida é estar contribuindo para o fortalecimento deste local.

Mas, afinal, o que é a APNB?

\section{BREVE HISTÓRICO}

Para o desenvolvimento dessa discussão foi fundamental o apoio da Profa. Marluce de Lima Macêdo ${ }^{3}$ que possibilitou acesso a arquivos pessoais (textos, vídeos, atas, convites, planos de ação, etc.), material essencial para a pesquisa em curso. Tive acesso ao texto da conferência de encerramento do II Congresso Baiano de Pesquisadores(as) Negros(as) - CBPN, proferido por ela no dia 26 de setembro de 2009, na Universidade Estadual de Feira de Santana - Bahia. Encontrei nele informações importantes sobre a constituição da Associação.

Seção baiana da Associação Brasileira de Pesquisadores(as) Negros(as) ${ }^{4}$, a APNB foi fundada em 06 de novembro de 2004. Conforme o seu estatuto ${ }^{5}$, é uma associação civil sem fins lucrativos que se destina à defesa e divulgação de pesquisas realizadas, prioritariamente, por pesquisadores(as) negros(as) ${ }^{6}$, sobre temas de interesse direto das populações negras e todos os demais temas pertinentes à construção e ampliação do conhecimento humano. Começa a germinar quando ao retornar do II Congresso Brasileiro de Pesquisadores(as) Negros(as) / COPENE em São Carlos - São Paulo, em agosto de 2002, um grupo de mestrandos e mestrandas do Programa de Pós-Graduação em Educação e Contemporaneidade da Universidade do Estado da Bahia iniciou uma discussão sobre a necessidade de uma maior articulação entre os(as) pesquisadores(as) negros(as) da Bahia, que possibilitasse uma

\footnotetext{
${ }^{3}$ Profa. Dra. da Universidade do Estado da Bahia - UNEB. Vice-Presidente da Associação de Pesquisadores(as) Negros(as) da Bahia (biênio 2008/2009). Presidente da APNB (biênio 2012/2013).

${ }^{4}$ Para saber mais sobre a ABPN, ver: https://www.abpn.org.br/

${ }^{5}$ Ver site: : http://apnb.org.br/bin/view/APNB/Hist\%c3\%b3rico

${ }^{6} \mathrm{O}$ termo possui correspondência com o que denominamos “intelectuais negros(as)" e será discutido mais adiante. 
participação mais efetiva e ampliada destes(as) na Associação Brasileira de Pesquisadores(as) Negros(as) - ABPN e nos seus Congressos. Segundo a Profa. Marluce Macêdo

Os encontros, discussões e reflexões desenvolvidas pelo grupo, culminaram numa participação mais articulada e propositiva no III Congresso Brasileiro de Pesquisadores(as) Negros(as), em São Luís do Maranhão - setembro de 2004. Além de apresentarmos nossos trabalhos acadêmicos, levamos para esse Congresso duas proposições: de realizar o IV COPENE em Salvador, na Bahia e a indicação do nome do professor Wilson Mattos, para ocupar a $1^{\text {a }}$ VicePresidência da ABPN. Após debates e articulações ao longo deste Congresso, essas proposições foram acatadas e aprovadas pela Assembléia Geral. Viemos com a importante missão de realizarmos o IV COPENE. No entanto, voltamos fortalecidos, pois o pequeno grupo que se reunia até então foi bastante ampliado, com a participação de professores(as), estudantes e outros(as) pesquisadores(as) - que se articularam ao grupo durante o III COPENE ou depois dele. Esse "novo" Grupo formou o que chamávamos de Seção Baiana de Pesquisadores(as) Negros(as), e foi responsável pela criação e estruturação da Associação de Pesquisadores(as) Negros(as) da Bahia, bem como pela organização do IV COPENE, em setembro de 2006, em Salvador. Agora, razoavelmente ampliado, se transformou num grupo interinstitucional, interdisciplinar e diverso, porém, com projetos e objetivos comuns. (Excerto do texto proferido na Sessão de Encerramento do II Congresso de Pesquisadores Negros(as) da Bahia, em 26 de setembro de 2009, na Universidade Estadual de Feira de Santana - Bahia)

Destaco aqui, algumas dessas importantes figuras e suas respectivas instituições, para ilustrar essa nova realidade: Wilson Mattos (UNEB), Ana Célia da Silva (UNEB), Florentina Souza (UFBA), Nilo Rosa (UEFS), Valdélio Silva (UNEB), Marise Santana (UESB), Edson Santana (UEFS), Vanda Machado (UNEB), Ivy Mattos (UNEB), Romilson Souza (CEDIC), entre muitos outras/os que participaram ativamente desse momento decisivo para a APNB.

Seguí na leitura do texto e vi que a criação, fundação e organização da APNB culminou no seu registro oficial em 2004, tendo como sua primeira Diretoria executiva: Wilson Mattos Presidente, Valdélio Silva $-1^{\mathrm{o}}$ Vice-Presidente, Maria de Lourdes Siqueira $-2^{\mathrm{a}}$ VicePresidente, Marluce Macêdo - $1^{\text {a }}$ Secretária, Delcele Queiroz - 2a secretária, Romilson Souza - Tesoureiro. Desde então, a APNB tem envidado esforços para promover a congregação e o diálogo com pesquisadores(as) e instituições de pesquisas da Bahia, intensificando e ampliando o campo de debates sobre as relações étnico-raciais, com vistas a interferir ativamente nos vários setores da vida pública do estado e do país, bem como fortalecer uma rede de solidariedade entre populações negras. 
a) O Primeiro CBPN / Congresso Baiano de Pesquisaderes(as) Negros(as) foi realizado em Salvador, na Universidade Federal da Bahia (UFBA) nos dias 15, 16 e 17 de novembro de 2007. Teve como tema "Políticas Públicas e Populações Negras: Ações afirmativas, raça, gênero e culturas";

b) O Segundo foi realizado em Feira de Santana, na Universidade Estadual de Feira de Santana (UEFS) de 24 a 26 de Setembro de 2009 com o título "Outros caminhos das culturas afro-brasileiras: confluências, diálogos e divergências";

c) Tendo como tema a "Pesquisa Social e Ações Afirmativas para afrodescendentes", o III CBPN foi realizado em conjunto com o III Seminário Internacional Áfricas, numa parceria entre a APNB e o READI ${ }^{7}$, na Universidade do Estado da Bahia (UNEB), campus V, em Santo Antônio de Jesus;

d) O IV Congresso Baiano de Pesquisadores(as) Negros(as) foi realizado entre os dia 18 e 21 de setembro de 2013 na Universidade Federal do Recôncavo Baiano (UFRB) e teve como tema "Da educação básica à pós-graduação: perspectivas e estratégias para a construção de políticas afirmativas de gênero e raça";

e) O V CBPN foi realizado na Universidade Estadual do Sudeste da Bahia - UESB, campus de Jequié, entre 16 e 20 de novembro de 2015 e teve como tema "Produções culturais Afro-Brasileiras e diversidade: territorialidades, histórias e saberes". O evento foi articulado com o IV Encontro Estadual de Educação das Relações Étnicas, a XI Semana de Educação da Pertença Afro-Brasileira e o II Seminário do Mestrado em Relações Étnicas e Contemporaneidade da UESB;

f) O VI Congresso Baiano de Pesquisadores(as) Negros(as) foi realizado entre os dias 20 e 22 de setembro de 2017. O evento foi promovido pela Associação de Pesquisadores(as) Negros(as) da Bahia/APNB, pelo Programa de Mestrado Profissional em Ensino e Relações Étnico-Raciais (PPGER/UFSB), pelo Núcleo de Estudos Afro-brasileiros da UFSB, pelo Programa Multidisciplinar em Estudos Étnicos e Africanos da Universidade Federal da Bahia (Pós-Afro/UFBA) e pelo Órgão de Educação e Relações Étnicas da Universidade Estadual do Sudoeste da Bahia (ODEERE/UESB). O VI CBPN dialogou com os temas dos congressos anteriores e promoveu debates sobre as narrativas históricas e vivências da população negra no sul da Bahia:

\footnotetext{
${ }^{7}$ O READI - Rede de Estudos Africanos e da Diáspora foi formado a partir do I Seminário Internacional Áfricas: Historiografia Africana e Ensino de História, no ano de 2009, realizado nas cidades de Salvador/Ba e Florianópolis/SC. O READI tinha como preocupação central refletir/debater sobre novos caminhos da historiografia africana, o lugar da África na produção historiográfica contemporânea e seu ensino nas universidades brasileiras e africanas e na educação básica.
} 
g) Por fim, com o tema "Políticas, saberes e tecnologias afro-diaspóricas: insurgências nas contemporaneidades negras", o VII CBPN colocou em debate modos de insurgências negras que são produzidos/gestados nos espaços da afrodiáspora, forjando/inspirando/demandando a implementação de políticas públicas, a reinvenção dos saberes e os modelos de reordenamento de ocupação dos territórios físicos e simbólicos. $\mathrm{O}$ evento ocorreu entre os dias 17, 18 e 19 de julho de 2019, na UFBA.

Para a Profa. Marluce Macêdo, os CBPN's

representam, de alguma forma, a culminância de longas jornadas de reuniões, discussões, embates, negociações, parcerias mas, também, e principalmente, o desempenho coletivo e solidário dos próprios pesquisadores(as) negros(as), que têm encontrado toda espécie de dificuldades para suas construções, principalmente no que diz respeito às parcerias econômicas. (Texto proferido na Sessão de Encerramento do II Congresso de Pesquisadores Negros(as) da Bahia. Em 26 de setembro de 2009, na Universidade Estadual de Feira de Santana - Bahia)

Ressalto que a APNB, além dos Congressos, tem agregado os(as) pesquisadores(as) em reuniões, seminários e assembléias promovendo debates e reflexões não só do interesse das populações negras, mas de toda sociedade.

\section{Objetivos da APNB ${ }^{8}$}

Dentre seus principais objetivos, destaco: congregar os(as) pesquisadores(as) negros(as) baianos(as), acadêmicos(as) ou não, que trabalham com temas de interesse direto das populações negras no Brasil; assistir e defender os interesses da APNB e dos(as) sócios(as) perante os poderes públicos em geral; promover conferências, reuniões, cursos e debates sobre temas e questões diretamente ligadas a populações negras no Brasil; possibilitar publicações de teses, dissertações, artigos, revistas sobre assuntos relativos às culturas negras no Brasil e em toda diáspora; manter intercâmbio com associações congêneres do país e do exterior; defender e zelar pela manutenção da pesquisa com financiamento público e dos institutos de pesquisa em geral, propondo medidas para seu aprimoramento, fortalecimento e consolidação e propor medidas para as políticas públicas no estado e no país.

\section{UMA TERRITORIALIDADE ESPECÍFICA}

A APNB é resultado de uma ação coletiva de pesquisadores(as) negros(as) oriundos do Movimento Social Negro ou de outras experiências que tem como espaço privilegiado a

${ }^{8}$ Extraído do site: http://apnb.org.br/bin/view/APNB/Hist\%c3\%b3rico 
universidade, reconhecida como o lugar da produção e da reflexão crítica do conhecimento, lugar para o (re)conhecimento da cultura universal e das várias ciências, com a tarefa prioritária de produzir e divulgar o saber. Nesse sentido, caberia a ela o papel de formar a cidadania de maneira que a produção dos conhecimentos acadêmicos devesse estar comprometida com essa premissa, como eixo fundamental e princípio orientador de todas as pesquisas realizadas nas diferentes áreas.

A universidade é ainda o lugar da diversidade, lugar de (des)encontros, acordos e conflitos entre diferentes concepções de vida e visões de mundo. Está imersa em uma complexidade de regras, de relações racializadas com momentos e contextos de interação traduzidos em comportamentos subjetivos e/ou objetivos onde a presença negra pode ser aceita ou não, tolerada, valorizada, reprimida e/ou repelida, impactando nas experiências/produções e nos deslocamentos dos sujeitos. (SANTOS, 2012)

É o lugar de (re)apresentação de combates e disputas pelo poder, pela memória e pela história - lugar de fronteiras (in)visíveis, estabelecidas enquanto representações desiguais e hierárquicas, baseadas em separações dicotômicas e muitas vezes absolutistas dos diferentes e das diferenças que convivem nele, tendo sempre como referencia os grupos que hegemonizam o poder e ditam regras que pretendem como universais. No entanto, essas fronteiras não são representadas apenas pela dualidade, elas são espaços de trânsito, onde divergências e confluências são permitidas, onde as possibilidades de demarcação e (re)definição dos territórios são reais, assim como o surgimento e a instalação de territorialidades específicas. (SANTOS, 2012)

Privilegio, aqui, a noção culturalista de território apontada por Haesbaert (2003) que “prioriza a dimensão simbólico-cultural, mais subjetiva, em que o território é visto sobretudo como o produto da apropriação/valorização simbólica de um grupo sobre o seu espaço". (HAESBAERT, 2003, p. 13) Território, nesse caso, vai além de um substrato físico, material e incorpora relações de poder e estratégias identitárias.

Dessa forma, entendo a APNB como uma territorialidade específica, um território insurgente em permanente itinerância, organizado a partir deste lugar que é a universidade e das relações de fronteiras estabelecidas. Um lugar praticado, cruzamento de móveis que tece redes de solidariedade, compromissos e construções de conhecimentos ligados às temáticas sobre as populações negras na Bahia, firmando-se enquanto campo onde são construídas “trincheiras" acadêmicas e táticas de resistências coletivas (CERTEAU, 2008), referências epistemológicas e políticas na luta antirracista. Uma territorialidade envolvida num processo complexo que envolve uma multiplicidade de sujeitos/agentes, poderes, moldados pelo 
movimento de reconhecimento da importância estratégica do espaço e do território para a transformação do lugar. (HAESBAERT, 2003)

Considero este espaçotempo importante agente promotor de práticas emancipatórias para as populações negras, privilegiando as conexões em redes cotidianas de conhecimentos que "escapam silenciosamente às conformações dos lugares de querer e poder". (CERTEAU, 2008, p. 92) Uma territorialidade atravessada por memórias, afetos, linguagens, performances que ao mesmo tempo inventam experiências de espaço no cotidiano, onde grupos subalternizados, com suas mil maneiras de "caça não autorizada, táticas de resistência vão alterando objetos e códigos”. (CERTEAU, 2008, p. 100) Refiro-me às invenções cotidianas produzidas por estes(as) intelectuais negros(as), professores(as) que interpretam as políticas hegemônicas de formação docente, reconfigurando-as às suas maneiras de produzir novos conhecimentos, de gravar sucessos artísticos com suas táticas cotidianas, praticando uma arte subalternizada, “ordinária”. (CERTEAU, 2008)

\section{INTELECTUAIS NEGROS(AS) E CONHECIMENTOS CONTRA-HEGEMÔNICOS}

A hegemonia dominante impregna a vida cotidiana entrelaçando-se com a cultura e se inscrevendo na experiência vivida de cada sujeitopraticante. Ela é

resultado de um processo educativo. Isso significa dizer que o grupo dominante consegue transformar a sua concepção de mundo em concepção de mundo hegemônica através de processos educativos, já que os grupos sociais dominados acabam por ser educados na ideologia do grupo dominante, como nos leva a entender Gramsci. Assim, a educação constitui-se num meio de difusão da ideologia ou concepção de mundo hegemônicas. (MARÇAL, 2003, p. 63)

Contudo, a noção de hegemonia como supremacia de um grupo sobre outros nunca deve ser naturalizada nem compreendida como uma coisa dada e estática, mas sim como historicamente construída e permanentemente mantida. Assim, como existe a necessidade de manutenção da hegemonia pelo grupo dominante, existe também a possibilidade de construir a contra-hegemonia pelos grupos subalternizados em uma sociedade (MARÇAL, 2003).

Privilegio, neste estudo, o diálogo com autores(as) que de alguma forma abordam temas que reverberam na produção de conhecimentos contra-hegemônicos, que percorrem "subterrâneos", produzidos por sujeitospraticantes que se insurgem a partir de um conjunto desnivelado de relações de poder, encontrando sentidos nas “artes de fazer". Seguindo as pistas certeaunianas, são essas práticas cotidianas do tipo táticas, maneiras de fazer destes(as) intelectuais negros(as) que produzem pequenas fissuras nos discursos, "artes de dar golpes", “astúcias de caçadores” buscando contar a sua própria história, reconfigurando memórias, 
construindo hegemonias alternativas no campo educacional brasileiro. Esforços e contribuições daqueles(as) que estão, de uma forma ou de outra, fora, ou nas margens, dos termos da hegemonia específica (WILLIAMS, 1979).

Historicamente construída, a hegemonia é permanentemente mantida pelos grupos dominantes, contudo sua dinâmica possibilita abertura de espaçostempos para construções contra-hegemônicas, onde os grupos subalternizados organizam e sistematizam concepções de mundo ancoradas em projetos coletivos de transformação social. Ressalto, então, que "qualquer hegemonia, no sentido sempre dominante, jamais será total ou exclusiva. A qualquer momento, formas de política e cultura alternativas, ou diretamente opostas, existem como elementos significativos na sociedade" (WILLIAMS, 1979, p. 117) .

Sendo a construção da contra-hegemonia iniciada, também, no terreno educacional, aqui interessam a organização e sistematização das produções, discursos, memórias próprias e conhecimentos mobilizados/produzidos pelos(as) intelectuais negros(as) da APNB. São, além de reflexões, formas de atuação na tentativa de reverter a situação das populações negras no interior de uma sociedade marcada pela lógica perversa de um sistema social estratificado e estruturalmente racializado. Produções que expressam-se em lutas e insurgências desse grupo que articula a militância política e a produção do conhecimento sobre a realidade étnico-racial fundamentada em sua própria vivência racial, inserindo-se politicamente na luta antirracista e desafiando a universidade e os órgãos do Estado a implementarem políticas afirmativas, notadamente no campo da educação (OLIVEIRA, 2016).

O termo intelectual negro(a), neste texto, faz referência a uma presença estética, fenotipicamente menorizada dentro da academia, ou mesmo fora dela, que compõe o universo da produção intelectual no país.

Uma presença marcada, regulada e (des)conhecida pelo seu lugar de pertencimento racial. (...) $\mathrm{O}$ termo, intelectuais negros, ao mesmo tempo em que designa e diferencia, cria certa homogeneidade para um grupo de intelectuais particularizados pelo pertencimento racial e pela experiência de isolamento e discriminação. (MACÊDO, 2013, p. 26)

Entendemos os intelectuais negros como os ativistas, professores, músicos, artistas, lideranças religiosas, poetas, enfim, todas aquelas pessoas capazes de construir uma homogeneidade e consciência de grupo para a população negra, bem como capazes de apontar os caminhos da resistência e da reexistência. (COSTA, 2018, p. 120) Não é apenas alguém que lida com ideias. Intelectual é alguém que lida com ideias transgredindo fronteiras discursivas porque ele ou ela vê a necessidade de fazê-lo, é alguém que lida com ideias em sua vital relação 
com uma cultura politica mais ampla. (bell hooks, 1995; WEST, 1999; SAID, 1993; SANTOS, 2011) Ressalto o fato de que eles/elas atuam, enquanto sujeitos coletivos de seu próprio conhecimento científico, ocupando lugar de destaque no cenário acadêmico ou mesmo fora dele. Cientes do papel da universidade, enquanto lócus privilegiado da produção de conhecimentos, a APNB vêm potencializando suas intervenções nos processos de formação de professores(as), com o intuito de qualificá-los(as) em uma perspectiva educacional antirracista.

\section{Histórias orais de vida: "experiências" formativas}

Nesta pesquisa, penso a formação docente e os saberes que aí são mobilizados a partir dos estudos do cotidiano, entendendo os discursos e narrativas dos(as) intelectuais negros(as) como fundamentais na produção de conhecimentos no espaçotempo educativo chamado APNB. Falar sobre suas histórias de vida não é uma tarefa simples, requer sensibilidade, compromisso e ética no tratamento das fontes orais. O registro das vidas destes(as) intelectuais, suas maneiras de ser e ensinar, suas produções, práticas e memórias situam-se num campo movediço em que se cruzam os modos de ser do indivíduo e o mundo social, as instituições e diferentes atores, grupos e conflitos que fazem parte de seus cotidianos. O que daí emerge aponta para o processo de construção e reconstrução permanente das suas subjetividades como parte de uma luta que busca a transformação da sociedade e do social em direção a realidades plenas e mais justas.

Dessa forma, a história oral de vida, opção metodológica desenvolvida aqui vislumbrase como uma maneira de superar a mera aquisição de dados em favor de uma visão mais subjetiva das experiências destes(as) intelectuais negros(as) com as questões étnico-raciais. Entendo "experiência como aquilo que nos atravessa" (BONDÍA, 2002, p. 21), situa e produz saberes, inscrevendo caminhos nos seus cotidianos que, por sua vez, são constituídos e também atravessados por eixos hierarquizantes de poder - raça, gênero, classe, religião, etc. Tudo isso expõe a contingência e complexidade de tais processos.

Penso o sujeito da experiência como aquele espaço onde têm lugar os acontecimentos, contrária à ideia de um sujeito já plenamente constituído, a quem as experiências acontecem. A experiência é o lugar da formação do sujeito e, para tanto, precisamos dar conta dos processos históricos que, através do discurso, posicionam sujeitos e produzem suas experiências.

Para Joan Scott

Não são os indivíduos que têm experiência, mas os sujeitos é que são constituídos através da experiência. A experiência, de acordo com essa definição, torna-se, não a origem de nossa explicação, não a evidência autorizada (porque vista ou sentida) que fundamenta o conhecimento, mas sim aquilo que buscamos explicar, aquilo sobre o qual se produz conhecimento. Pensar a experiência dessa forma é historicizá-la assim como as identidades que ela produz $(1999$, p. 27) 
O estudo da experiência deve questionar sua posição enquanto origem na narrativa histórica, não a reprodução e transmissão de um conhecimento ao qual se chegou pela experiência, mas sim a análise da produção desse conhecimento. A atenção a esse ponto "revela a experiência como um lugar de contestação: um espaço discursivo onde posições de sujeito e subjetividades diferentes e diferenciais são inscritas, reiteradas ou repudiadas”. (BRAH, 2006, p. 361) Uma prática de atribuir sentido tanto simbólica como narrativamente.

Se o sujeito da experiência é aquele espaço onde têm lugar os acontecimentos, aquilo que nos toca (BONDÍA, 2002) e a experiência revela-se como um espaço discursivo, de formação do sujeito, pergunto: Que processos educativos presentes na trajetória de vida de pessoas negras as formam intelectuais negros(as)? De que forma as esperiências com as questões raciais localizam discursivamente as produções de intelectuais negros(as) dentro e/ou fora dos espaços formativos da APNB?

\section{Histórias orais de vida: encontros polifônicos}

Uma das razões primordiais para utilização da entrevista na perspectiva da história oral reside no fato dela possibilitar o estabelecimento de uma conversação ou um diálogo entre informante e analista, pesquisador(a) e sujeito, procedimento que acontece no tempo real da apreensão e que para tanto necessita de personagens vivos colocados em uma situação dialógica. (MEIHY; HOLANDA, 2007) Uma grade de procedimentos que privilegia o diálogo, requerendo atenção à polifonia discursiva que emerge destes encontros.

Perceber polifonias no discurso requer além de sensibilidade, responsabilidade com relação aos depoimentos que serão colhidos, com os fragmentos de vida falados aos ouvidos, elementos permeados por um conjunto de compromissos, experiências e atuações marcadas por recuos, avanços, radicalidades, empolgações e persistências destes(as) intelectuais negros(as). Lidar com estas fontes polifônicas é atentar para os processos históricos que nelas estão imbricados.

Uma fonte polifônica será aquela na qual se expressam efetivamente diversas vozes - por vezes explicitamente, através de um espaço que lhes é concedido para a fala; por vezes implicitamente, através do discurso de um outro que mesmo sem querer termina por permitir que outras vozes falem no interior de seu discurso. (BARROS, 2012, p. 24)

Entrevendo as narrativas desse grupo de intelectuais negros(as) que compõem a APNB, vou desenvolvendo o entendimento de que suas falas são atravessadas por uma polifonia que os constitui, nos fazendo perceber as múltiplas vozes, desconstruindo a ilusão de unidade que se apresenta nos seus enunciados. Assim, as potencialidades dos aspectos dialógicos e 
polifônicos (BAKHTIN, 1997) aqui propostos possibilitarão antever, além de pontos de encontro, algumas tensões entre suas falas. Lançando mão destas perspectivas, busco garantir

um posicionamento político-epistemológico bastante diverso do que o institucionalizado pela ciência moderna, de uma forma geral, e pela educação escolar formal, de uma forma mais específica, possibilitando, consequentemente, um diálogo com saberes fazeres histórica e socialmente invisibilizados. (JÚNIOR; JÚNIOR; PASSOS, 2012, p. 6)

A entrevista em história oral pressupõe a realização de relações simétricas e colaboração entre pesquisador(a) e sujeito, favorecendo um depoimento mais espontâneo e interativo, construído dentro de uma relação empática que estimula a reflexão, a afetividade e a memória (MEIHY, HOLANDA, 2007).

Acredito que as entrevistas narrativas possibilitam o estímulo certo ao(a) entrevistado(a) elaborar uma narrativa improvisada acerca de um assunto que possa surgir no transcorrer da conversa, de modo que nela apareçam elementos importantes para lançar luz ao tema das questões étnico-raciais. O que a caracteriza é a ênfase na produção das melhores condições possíveis para a emersão de uma narrativa livre, na qual o(a) entrevistado(a) possa transitar entre as próprias memórias e vivências.

As narrativas orais não são apenas fontes de informações para o esclarecimento de problemas do passado, ou um recurso para preencher lacunas da documentação escrita. Ganham relevância as vivências e as representações individuais. As experiências dos homens e mulheres, constitutivas de suas trajetórias, são rememoradas, reconstruídas e registradas a partir do encontro de dois sujeitos: narrador(a) e pesquisador(a).

Acredito que a história oral de vida possibilite a transmissão da experiência via narrativas, onde o ordenamento dos fatos e o estabelecimento de relações de sentido e causalidade ficam a cargo do(a) entrevistado(a).

\section{HISTÓRIAS ORAIS DE VIDA: POTENCIALIDADES METODOLÓGICAS}

Entrevista em história oral é a manifestação do que se convencionou chamar de documentação oral, ou seja, suporte material derivado de linguagem verbal expressa para esse fim. É um processo de aquisição de entrevistas inscritas no tempo presente e deve responder a um sentido de utilidade prática, social e imediata. A documentação oral, quando apreendida por meio de gravações eletrônicas feitas com o propósito de registro torna-se fonte oral. A História oral é uma parte do conjunto de fontes orais e sua manifestação mais conhecida é a entrevista.

Ponto importante no trabalho com histórias de vida é aquele que toca na questão da visibilidade das recordações dos sujeitos. Tal perspectiva lança-se como uma fina luz, na tentativa de ultrapassar a espessa camada que "blinda" a história compreendida apenas pelo 
prisma dos grandes espetáculos criados e historicizados pelas elites, buscando dessa forma pela própria história lançar vida pra dentro da história. Segundo Macedo, “o recurso da história de vida nos meios educacionais é mais uma contribuição para o rompimento com o baixo mimetismo cognitivo, o abstracionismo teórico e o colonialismo intelectual (...)” (MACEDO, 2004, p. 177) Esses fatores, capturados por uma ética burguesa e um por uma técnica balizada no cientificismo moderno, como idéia reguladora hegemônica de produção do único conhecimento válido praticaram e praticam ainda uma epistemologia e uma metodologia extremamente excludentes.

O termo história de vida abarca procedimentos e aproximações extremamente diversos. É possível afirmar que, na atualidade, existe certo consenso sobre a riqueza oferecida por esse trabalho.

Este reside em outorgar um lugar de privilégio à experiência vivida, em sentido longitudinal, e em possibilitar a integração de percepções individuais e pautas universais de relações humanas, através de articulações temporais. Neste sentido, o trabalho sobre as experiências dos sujeitos é fundamental para a compreensão dos atores a partir de seus próprios pontos de vista e para a compreensão de processos sociais mais amplos que os indivíduos. (CAMARGO, 1993, p. 18)

Acredito que a importância dada à "experiência" seja uma das riquezas contidas no trabalho com histórias de vida e de extrema importância na pesquisa aqui proposta. Reconstruir trajetórias de vida significa recuperar os diferentes sentidos e significados que os sujeitos dão às suas experiências e o modo como constroem e reconstroem suas próprias identidades. Falar de si é dizer do lugar em que se vive e do modo como uma subjetividade se constrói na relação com os outros e com o mundo. O olhar do entrevistado, voltado às suas experiências de vida, retoma momentos que ficaram como "marcas" em seu corpo; por isso, relembrar é recuperar um amontoado de lembranças de pessoas, lugares e afetos e revolver aquilo que ficou aparentemente esvaziado de vida, mas, paradoxalmente, impregnado de vida e de vivências.

$\mathrm{O}$ ato de falar de si através de narrativas é o próprio ato de recordar. Narrar é mergulhar as palavras em experiências vividas, as quais são carregadas de conceitos, é movimentar a racionalidade e a subjetividade individual no coletivo. Para os acontecimentos narrados não há uma única versão, convidando os ouvintes a criarem outras, com significações nascidas de uma narrativa inconclusa. (BENJAMIN, 1993)

\section{CONSIDERAÇÕES FINAIS}

Neste texto, apresentei algumas reflexões acerca das possíveis contribuições da Associação Baiana de Pesquisadores(as) Negros(as) - APNB e intelectuais negros(as) para o 
campo temático da educação das relações étnico-raciais na formação inicial e continuada de professores(as).

Mesmo sendo uma abordagem preliminar da pesquisa que desenvolvo, acredito na sua importância por entender que a APNB tem como função o preparo de professores(as) para atender a demanda diversificada de estudos das relações étnico-raciais, no que se refere ao trabalho educativo antirracista e as formações iniciais e continuadas de professores(as) são elementos fundamentais para isso.

Entendemos que as universidades, os institutos federais de educação, ciência e tecnologia, se constituem como lócus privilegiado de formação docente, nas suas dimensões inicial e continuada e que precisam fazê- lo na perspectiva da educação antirracista. Essa é uma demanda importantíssima de várias organizações do movimento negro e do segmento afrobrasileiro que se reconhecem como alocados em posição de subalternidade e que desejam romper com essa assimetria relacional.

Pretendo que as reflexões suscitadas neste texto fortaleçam novas construções/reconstruções que visem à promoção da qualidade de vida de todos os envolvidos e possíveis caminhos institucionais de uma efetiva política de/para a diversidade e na/da inclusão multi, inter e/ou transcultural, favorecendo a construção da justiça social e da cidadania.

Destaco a importância desta pesquisa na perspectiva dos estudos do cotidiano, entendendo que a atenção dada às histórias de vida de intelectuais negros(as), suas narrativas, discursos e produções são importantes para o fortalecimento daqueles espaços que agrupam e estudam o campo da formação de professores(as) e as relações raciais, promovendo a ampliação de uma educação mais igualitária e justa.

\section{REFERENCIAS}

ALVES, Nilda. Decifrando o pergaminho - o cotidiano das escolas nas lógicas das redes cotidianas. In: OLIVEIRA, Inês Barbosa; ALVES, Nilda. Pesquisa nos/dos/com os cotidianos das escolas: sobre redes de saberes. Petrópolis/RJ: DP et Alii, 2008

; OLIVEIRA, Inês Barbosa de. Imagens de escolas: espaçostempos de diferenças no cotidiano. Educ. Soc., Campinas, vol. 25, n. 86, p. 17-36, abril 2004. Disponível em: $<$ http://www.cedes.unicamp.br $>$

BAKHTIN, Mikhail Mikhailovich. Estética da Criação Verbal. São Paulo: Martins Fontes, 2000.

BARROS, José Costa D'assunção. O tratamento historiográfico de fontes dialógicas. Revista Expedições: Teoria da História \& Historiografia. Ano 3, N.4, Julho 2012. 
BENJAMIM, Walter. (1993). Magia e técnica, arte e política: ensaios sobre literatura e história da cultura. Trad. de Sérgio Paulo Rouanet, prefácio de Jeanne Marie Gagnebin, $7^{\text {a }}$ ed., São Paulo, Brasiliense.

BONDÍA, Jorge Larrosa. Notas sobre a experiência e o saber de experiência. Tradução de João Wanderley Geraldi; Universidade Estadual de Campinas, Departamento de Lingüística. $\mathrm{Jan} / \mathrm{Fev} / \mathrm{Mar} / \mathrm{Abr} 2002 . \mathrm{N}^{\mathrm{o}} 19$.

BRAH, Avtar. Diferença, diversidade, diferenciação. Cadernos Pagu - Núcleo de Estudos de gênero. UNICAMP - Campinas, nº 26, janeiro-junho, 2006.

CAMARGO, Aspasia. Os usos da história oral e da história de vida: trabalhando com elites políticas. Dados, Revista de Ciências Sociais, v. 27, n. 1, p. 5-29, 1984.

CARDOSO, Paulino. As ações afirmativas e os desafios da luta pela igualdade na conjuntura atual. Chapecó. Ed. Revista Pedagógica, (jan./abr) 2017. V. 19, nº 40, , p. 33-42.

. Os núcleos de estudos afro-brasileiros e a associação brasileira de

pesquisadores(as) negros(as): desafios. ABPN 10 ANOS. I Seminário Virtua: Seminário Estratégico de Fortalecimento Institucional da ABPN. 2013, p. 21-25.

CERTEAU, Michel de. Artes de fazer. A invenção do cotidiano. Petrópolis, RJ. Vozes, 1998.

COSTA, Joaze Bernardino. Decolonialidade, Atlântico Negro e intelectuais negros

brasileiros: em busca de um diálogo horizontal. Revista Sociedade e Estado - Volume 33, Número 1, Janeiro/Abril 2018

FERRAÇO, Carlos Eduardo; GOMES, Marco Antônio Oliva. Políticas da diferença nos cotidianos escolares: ou sobre problematizações das práticas curriculares com ênfase na diversidade. In: Práxis Educacional Vitória da Conquista v. 11, n. 20 p. 271-289 set./dez. 2015

FONSECA, Maria Nazareth Soares. (org.). Brasil afro-brasileiro. $2^{\text {a }}$ Ed. Belo Horizonte: Autêntica, 2001, 352 p.

GROSFOGUEL, Ramón. Para descolonizar os estudos de economia política e os estudos pós-coloniais: Transmodernidade, pensamento de fronteira e colonialidade global. Revista Crítica de Ciências Sociais, 2008

HAESBAERT, Rogério. Da desterritorialização à multiterritorialidade. In: Boletim gaúcho de Geografia. Porto Alegre, vol. 29, no 1. P. 11-24, Jan - Jun, 2003.

HOOKS, bell. Intelectuais negras. Revista Estudos Feministas. v. 3, n. 2 (1995).

MACEDO, Marluce de Lima. Intelectuais Negros, Memória e Diálogos para uma Educação Antirracista: uma leitura de Abdias do Nascimento e Edison Carneiro. Tese (Doutorado), Salvador, BA, 2013.

MACEDO, Roberto Sidnei. A etnopesquisa crítica e multirreferencial nas ciências humanas e na educação. $1^{\circ}$ Edição. Ed. EDUFBA, 2000.

MARÇAL, José Antônio. A formação de intelectuais negros(as): políticas de ação afirmativa nas universidades brasileiras. Belo Horizonte: Nandyala, 2012.

MENESES, Maria Paula, SANTOS, Boaventura de Sousa. Epistemologias do Sul. Biblioteca Nacional de Portugal, jan. 2009.

OLIVEIRA, Inês B. O Currículo como criação cotidiana. Petrópolis, RJ: DP et Alli, 2012 
OLIVEIRA, Otair Fernandes de. Intelectualidade Negra e produção do conhecimento na Educação Brasileira. In: Revista ensaios e pesquisa em Educação. Vol. 01. Segundo semestre. 2016. P. $106-118$.

PASSOS, Mailsa Carla Pinto. Encontros cotidianos e a pesquisa em Educação: relações raciais, experiência dialógica e processos de identificação. Educar em Revista, Curitiba, Brasil, n. 51, p. 227-242, jan./mar. 2014. Editora UFPR.

SAID, Edward. Representações do intelectual: as Conferências Reith de 1993. Tradução Milton Hatoum. - São Paulo : Companhia das Letras, 2005.

SANTOS, Sales Augusto dos. A metamorfose de militantes negros em negros intelectuais. Revista Mosaico. Disponível em: file://C:/Users/gusta/Downloads/62800-134944-2-PB.pdf. Acessado em: 2 de setembro de 2017.

SCOTT, Joan. “Experiência”. In. DA SILVA, Alcione Leite, LAGO, Maria Coelho de Souza, RAMOS, Tânia Regina Oliveira. Falas de gênero: Teorias, análises, leituras. Florianópolis: Ed. Mulheres, 1999.

MULLER, Tânia Maria pedroso. Negras e negros: pesquisas e debates. In: SANTOS, Renato Emerson dos (org.). Questões urbanas e racismo. Petrópolis RJ : DP et Alii ; Brasília, DF : ABPN, 2012. 400p.

WEST, Cornel. "The dilemma of the Black Intellectual”. In.: AUTOR. The Cornel West: reader. Basic Civitas Books, 1999, p. 302-315. (Tradução e notas de Braulino Pereira de Santana, Guacira Cavalcante e Marcos Aurélio Souza).

WILLIAMS, Raymond. Marxismo e literatura. Rio de Janeiro: Zahar, 1979. 